\title{
Sexuality and Menopause, a Belgian Study
}

\author{
Nicolas Zdanowicz ${ }^{1 *}$, Denis Jacques ${ }^{1}$, David Tordeurs ${ }^{1}$, Pierre Schepens ${ }^{2}$, Christine Reynaert ${ }^{1}$ \\ ${ }^{1}$ Catholic University of Louvain, Yvoir, Belgium \\ ${ }^{2}$ Clinic of the Forest of Soigne, Bruxelles, Belgium \\ E-mail: "nicolas.zdanowicz@uclouvain.be
}

Received August 29, 2011; revised September 26, 2011; accepted October 15, 2011

\begin{abstract}
Aim: Until the 1980s, due largely to prejudice, post-menopausal women were believed to experience significantly less sexual desire and thus to have sexual intercourse less often than before menopause. Since the 1990s, this type of prejudices seems to have decreased. The aim of our study is to examine the sexuality of post-menopausal women by comparing it to same aged men's sexual behaviour and the importance of sexuality in their life. Methods: A sample of 1526 women and 1151 men aged 55 and over. Results: Female subjects reported having sexual intercourse as often as women in the general population (once a week for $64 \%$ of them). The same proportion of women as men consider that a successful sexual life: is essential for a successful couple life (90\%), needs continuous creativity (80\%), has a deep positive impact on their well-being (87\%). For most of them (82\%), a satisfying sex life is possible only if there is a deep love relationship. 55\% say they have never met sexual problems. The main complaints cited are vaginal dryness (45\%) and a lack of desire (42\%). Only $20 \%$ of those who had sexual problems report that age and time passing by are responsible for their troubles. In second place, they mention stress (19\%), followed by relationship problems, and nervous breakdown (13\%). Conclusion: Our study suggests that nowadays, there is no marked difference between post-menopausal women and men's sexuality either in terms of frequency, or in terms of its importance in their life. Whenever physical problems linked to sexuality arise, they are more often attributed to stress added to relationship problems rather than to ageing. This study shows once again how sexuality is influenced by prejudices.
\end{abstract}

Keywords: Menopause, Sexuality, Health

\section{Introduction}

Sexuality in societies varies over time. In a previous article [1] we have shown that in the West, at least since the 1930 s, it is young women who change socio-cultural relations to sexuality. This was true until the early 1980s AIDS crisis, when after a brief return to a more controlled sexuality, the internet has replaced women as an engine of attitudinal and behavioral changes toward sexuality. The influence of the Internet on young people has therefore attracted much of researchers' attention in recent years $[2,3]$. This increased attention may hide another phenomenon: since the early 2000s, the women who participated in the Sexual Revolution are reaching the age of menopause. If the sexuality of young people is so much subject to changes, the same may be true for elderly people...

In a recent review of the literature Hillman [4] has shown that knowledge about sexuality among seniors is limited. Despite that nowadays some information does exist on menopausal women' sexuality $[5,6]$, it is always conceived in terms of a declining sexuality that is significantly more pronounced in women than in men of the same cohort. This declining interest was supposed to be of biological (hormonal) and psychosocial origins, underpinned by a sexuality that is no longer necessary for procreation. This type of reasoning is questionable for two reasons. First, the influence of hormones on human sexuality is far from clear [7] and second, human sexuality exceeds the simple reproductive function [8]. Delamater \& Sill [9] have also demonstrated that, in contrast to those assumptions, elderly women's sexual desire and interest can be considerable. Accordingly, since the women of the "Sexual Revolution" are now older 55 years old, our research explores whether differences exist among men and women of the same generation. Three 
areas of sexuality were compared:

1) Sexual behaviours: frequency and urge,

2) The place of sexuality in couple life,

3) Sexual difficulties.

\section{Method}

\subsection{Questionnaires}

In Belgium there is a yearly Fair on seniors' health and recreational activities [10]. We took advantage of the 2006 Fair to ask men and women 8 questions about their sexuality. At the exhibition entrance, the questionnaire was anonymously offered to visitors, who were free to answer it or not. The filled questionnaires were then put in a sealed ballot box. The 8 questions are presented in the "Results" section. The questionnaire has not been validated outside of this first test.

\subsection{Subjects}

1526 women (57\%) and 1151 men (45.1\%) answered the questionnaire.

\subsection{Statistics}

The differences in distributions are measured with Pearson's chi-square test. All statistics are two-tailed. The thresholds of significance are 0.05 and 0.95 . No post-hoc test was performed.

\section{Results}

\subsection{Epidemiologic Data}

The mean age was 61.3. Women were 60 on average (three were older than 75 ). 92.7\% of men and women declared being in a stable relationship $\mathbf{7 7 . 7 \%}$ for more than 10 years). $74.3 \%$ declared it was their first marriage. $64.2 \%$ were retired.

\subsection{Sexual Behaviors: Frequency of Sexual In- tercourses and Urges}

For men and women, the mean number of sexual attempts was 5.7 a month (median: 4.0). Only 14\% declared not having had sexual attempts anymore. No significant differences $\left(x^{2}\right)$ were observed between men and women's frequency of sexual intercourse (Table 1), between men and women's rejection of the beliefs that the desire for sexual intercourse diminishes in a couple over the years (Table 2), or the view that sex is "just a habit" (Table 3).
Table 1. On average, how often have you had sexual intercourse in the past 4 weeks?

\begin{tabular}{lcc}
\hline & Men\% (N) & Women\% (N) \\
\hline Never & $10(138)$ & $14(214)$ \\
Once a month & $22(256)$ & $23(343)$ \\
Once a week & $37(432)$ & $38(580)$ \\
Twice to four times a week & $27(272)$ & $21(321)$ \\
Five to ten times a week & $3(37)$ & $3(47)$ \\
More than ten times a week & $1(16)$ & $1(21)$ \\
\hline
\end{tabular}

Table 2. As the years go by, the desire to make love fades in a couple.

\begin{tabular}{lcc}
\hline & Men\% (N) & Women\% (N) \\
\hline Totally disagree & $11(134)$ & $12(183)$ \\
Disagree & $26(274)$ & $23(343)$ \\
Agree & $48(543)$ & $47(715)$ \\
Totally agree & $16(200)$ & $19(285)$ \\
\hline
\end{tabular}

Table 3. To be satisfactory, sex life with my partner/husband (wife) often requires renewed creativity.

\begin{tabular}{lcc}
\hline & Men\% $(\mathrm{N})$ & Women\% $(\mathrm{N})$ \\
\hline Totally disagree & $3(49)$ & $5(81)$ \\
Disagree & $13(158)$ & $15(223)$ \\
Agree & $53(604)$ & $52(790)$ \\
Totally agree & $31(340)$ & $28(432)$ \\
\hline
\end{tabular}

\subsection{The Place of Sexuality}

The importance of sexuality is investigated in two areas: personal life (Table 4) and couple relationship (Table 5). Conversely, to investigate the mythical "cougar-woman" - the so called adept of a sexuality devoid of affection [11], one question concerned the importance of feelings in a couple's life (Table 6). Although more than $87 \%$ of women believe that sex is necessary for their well being and provides security in the couple life, they-as did their male partners-attached great importance to feelings of love. 82 percent believe that a satisfying sex life is possible only in the context of a deep loving relationship.

Table 4. Do you consider that a successful sex life has a significant impact on your well-being?

\begin{tabular}{lcc}
\hline & Men\% (N) & Women\% (N) \\
\hline Totally disagree & $2(33)$ & $4(60)$ \\
Disagree & $7(92)$ & $9(140)$ \\
Agree & $43(494)$ & $43(652)$ \\
Totally agree & $49(532)$ & $44(674)$ \\
\hline
\end{tabular}

Table 5. Do you think that a harmonious sex life is essential for a successful couple life?

\begin{tabular}{lcc}
\hline & Men\% (N) & Women\% (N) \\
\hline Totally disagree & $4(40)$ & $4(56)$ \\
Disagree & $4(40)$ & $7(101)$ \\
Agree & $40(465)$ & $45(687)$ \\
Totally agree & $53(605)$ & $45(684)$ \\
\hline
\end{tabular}


Table 6. Do you think that a satisfying sex life is possible only in a deep love relationship?

\begin{tabular}{lcc}
\hline & Men\% $(\mathrm{N})$ & Women\% $(\mathrm{N})$ \\
\hline Totally disagree & $3(46)$ & $5(73)$ \\
Disagree & $10(134)$ & $13(197)$ \\
Agree & $47(494)$ & $39(601)$ \\
Totally agree & $40(478)$ & $43(655)$ \\
\hline
\end{tabular}

\subsection{Sexual Difficulties}

To the question: "during your sexual activities, have you experienced: vaginal dryness, lack of desire, lack of pleasure, another difficulty, none," approximately one in two women reported experiencing a sexual problem. The most frequently reported ones are vaginal dryness and lack of desire (30\%), followed by lack of pleasure. This result corroborates one of Kingsberg's findings [12]. Women who reported sexual problems cited age as the first causal factor (20\%) followed by stress, depression and problems in their couple (Table 7). The cumulative weight of these last three factors is twice higher than age (46\%/20\%). For almost $50 \%$ of women, the sexual dysfunction had an impact on their couple relationship, and $30 \%$ reported to be afraid to raise this issue with their partner.

\section{Discussion}

In our study, no significant difference was found between menopausal women and same age men. Different explanations are possible to interpret this finding. In addition to our hypothesis that the change in the sexuality of postmenopausal women is due to women of the sexual revolution coming of age, other interpretations are possible. For example, lacking previous research findings, we cannot advance that such a difference between women and men never existed other than in social myths. Another possibility is that the increase in hormonal replacement therapies has reduced these differences. Our findings might also result from a bias for the women in our sample for two reasons:

1) They live mostly as a couple and, in contrast, in

Table 7. Do you think that sexual difficulties are usually due to the following items?

\begin{tabular}{lc}
\hline & $\%$ \\
\hline Depression & 14 \\
Relational problems & 13 \\
Stress & 19 \\
Age & 20 \\
Other causes & 10 \\
Alcohol abuse & 7 \\
Hypertension & 5 \\
Being Overweight & 5 \\
Tobacco abuse & 4 \\
Diabetes & 4 \\
\hline
\end{tabular}

Belgium 602,262 women beyond 65 are single versus 473,682 who live in couples [13]. In other words, single women were under represented in our sample. This sampling bias might be important since, as Hillman suggests, [11] the sexual behavior of older single people is more accepted today than in the past and have probably change.

2) They were generally healthier than experimental subjects usually studied in medical research designs. In many cases, women who are studied by such research are recruited because of health problems. Women in our study were recruited in a recreational environment.

We obviously cannot know which of the above interpretations is correct, and our finding (assuming that it qualifies as one) probably resulted from all these causes.

In conclusion our study tends to show that nowadays, there is no marked difference between post-menopausal women and same age men's attitudes toward sexuality, either in terms of frequency, or in terms of importance of sexual intercourse in their life. This finding illustrates once again the influence of social prejudice on sexuality, and shows the continuous importance of sex therapy and couple therapy.

\section{References}

[1] N. Zdanowicz, A. Crochelet, D. Jacques and Ch. Reynaert, "Interactions between Internet and Adolescents' sexual development," In: H. O. Price, Ed., Internet Addiction, Nova Publishers, New York, 2011, pp. 59-69.

[2] N. Zdanowicz and Ch. Reynaert, "Medicine Student's Knowledge En Sexology and Their Use of the Internet," European Journal of Sexual Health, Vol. 16, No. 2, 2007, pp. 121-131.

[3] Y. Salmon and N. Zdanowicz, “Net, Sex and Rock’n'roll! The Potentialities of a Tool Like the Internet and Its Influences on a Teenagers' Sexuality,” European Journal of Sexual Health, Vol. 54, No. 3, 2006, pp. 1158-1360.

[4] J. Hillman, "Sexual Issues and Aging within the Context of Work with Older Adult Patients," Professional Psychology: Research and Practice, Vol. 39, No. 3, 2008, pp. 290-297. doi:10.1037/0735-7028.39.3.290

[5] T. Ginsberg, S. Pomerantz and V. Kramer-Feeley, "Sexuality in Older Adults: Behaviours and Preferences,” Age and Ageing, Vol. 34, No. 5, 2005, pp. 475-480. doi:10.1093/ageing/afi143

[6] Ch. Reynaert, E. Verreckt, D. Tordeurs, N. Zdanowicz and M. Van Houtte, "La vie Affective et Sexuelle Après 50 Ans,” Belgian Journal for Sexual Health, Vol. 1, No. 6, 2004, pp. 12-17.

[7] Ch. Reynaert, N. Zdanowicz, P. Janne and D. Jacques, "Depression and Sexuality," Danubina Psychatria, Vol. 22, Supple- ment 1, 2010, pp. 111-113.

[8] Ch. Reynaert, D. Jacques and N. Zdanowicz, "Comment Communiquer en Sexologie: Une Reflexion Ethique,” 
Louvain Medical, Vol. 128, No. 6, 2009, pp. 101-105.

[9] J. D. Delamater and M. Sill, "Sexual Desire in Later Life,” The Journal of Sex Research, Vol. 42, No. 2, 2003, pp. 138-149. doi:10.1080/00224490509552267

[10] V. Algrain, N. Zdanowicz, Ch. Reynaert and F. Godenir, "La vie Affective et Sexuelle des Belges Après 50 Ans: Présentation de L'étude Epidémiologique 'Zenith 2005'," Louvain Medical, Vol. 125, No. 4, 2006, pp. 107-115.

[11] J. L. Hillman, "Clinical Perspectives on Ederly Sexuality," Kluwer/Plenum, New York, 2000.
[12] S. Kingsberg, "The Impact of Aging on Sexual Function in Women and Their Partners," Archives of Sexual Behavior, Vol. 31, No. 5, 2002, pp. 431-437. doi:10.1023/A:1019844209233

[13] INASTI, "Population Par Sexe, Groupe D’âges et Par Etat Civil Pour La Belgique et Les Régions,” 2010. http://statbel.fgov.be/fr/statistiques/chiffres/population/str ucture/etatcivil/popreg/ 